\title{
13. An alternative reply to the free-rider objection against unconditional citizenship grants
}

\author{
Julia Maskivker
}

\section{Introduction}

A powerful objection against unconditional welfare benefits is the so-called 'free-rider argument'. This objection is based on considerations of justice. It tells us that it is unjust that some people benefit from the efforts of others without contributing to the common enterprise from which all stand to gain (Elster 1986). This line of accusation is usually directed to left-libertarian defences of stake-holding proposals such as the basic income scheme, which, if sufficiently generous, could substantially relax the necessity to work for a livelihood through a universal, non-means-tested grant. The free-rider objection against unconditional welfare provisions reads like this: why should people who work devote part of the fruits of their efforts to paying taxes to finance the unconditional welfare benefits of those who opt not to work when they perfectly could? Allowing for this possibility, the argument goes, amounts to exploitation, understanding the latter as taking advantage of someone else's efforts without contributing to the creation of common benefits. ${ }^{1}$ The objection conveys the idea that free-riders breach an important principle of reciprocity by obtaining the fruits of the efforts of others and contributing nothing themselves in return.

Defenders of the basic income scheme have responded that insofar as the option to exit cooperation is equally available to everybody, there are no reasons to suspect injustice. One reply to the view that living off other people's work is a case of injustice is to deny that living off other people's work is unjust when everybody is given the same possibility (Van der Veen 1991, p. 200). In this sense, equal distribution of the free-riding option is sufficient to consider free-riding just. When all face the same possibility, defenders of the basic income scheme say (Van der Veen and Van Parijs 1986, p. 726):

\footnotetext{
1 'Exploitation' is understood in a non-technical way, that is, not as the unequal exchange between employer (or capitalist) and employee (or worker) but more generally as a benefit produced by illegitimately taking advantage of someone's efforts.
} 
some will choose little or no paid work, while others will want to work a lot, whether for the additional money or for the fun of working, thereby financing everyone's universal grant. If the latter envy the former's idleness, why don't they follow suit?

The preceding argument has been viewed as flawed because it does not speak to the fundamental concern that motivates the exploitation objection, namely, that free-riding is by nature unjust regardless of how many individuals are in a position to engage in it. It cannot always be enough, in assessing the justness of a given state of affairs, to evoke a distributive criterion as the primordial index of fairness. When defenders of the exploitation objection against the basic income scheme, or unconditional welfare goods in general, argue that escaping cooperation while receiving the benefits of it is unjust, they point to the nature of this injustice irrespective of how extended the injustice is. They wish to condemn what they understand to be an illegitimate advantage based on the violation of fairness considerations; they do not criticise the actual allocation of opportunities. They think that the individual who gains from a common practice without making a contribution in return when he or she is physically able to is arrogating to himself or herself unjustified preferential treatment (Cullity 1995). ${ }^{2}$

However, defenders of the basic income scheme have provided a more 'principled' response to the free-rider objection. In particular, Philippe Van Parijs offers a powerful argument to counteract the claim that non-conditionality is unfair: the argument of a fair share to natural resources. ${ }^{3}$ Defenders of the exploitation objection, nevertheless, still press their objections of fairness against Van Parijs's line of reasoning. Considerations of fair reciprocity, they argue, trump rights to initially unowned natural resources that require labour and already developed technologies to be made use of in any meaningful way. ${ }^{4}$

In the framework of this heated debate, this chapter aims to provide an alternative response to the free-rider argument; one that has been consistently under-explored in discussions about social reciprocity and fairness. Drawing significantly on H. L. A. Hart's and John Rawls's thinking on cooperative obligations, in this chapter I claim that freedom from cooperation in the generation of social benefits is justified on the basis of two considerations,

\footnotetext{
2 Cullity alludes to this line of reasoning, although he defends the idea that free-riding can be moral under certain circumstances.

3 The argument is that people have basic entitlements, and among these entitlements is an entitlement of each member of society, or of humankind, to an equal share in the natural resources. The claim is that this leads to the justification of a basic income at a level that would match the competitive value of an equal share of these resources. This view of justice is based on these equal entitlements in land plus the ownership of each person by that person. See Van Parijs (1995), and his later work more generally, for a complete account of this perspective.

4 See, paradigmatically, White (2004).
} 
namely, injustice in the design of the cooperative scheme and the non-voluntary nature of that scheme. The latter is explained by the fact it is impossible to abandon employment on pain of deprivation. The former relates to the claim that access to self-realisation through the use of human talents and dispositions is unequally distributed in society. I claim that society's failure to provide minimal opportunities for self-realisation imposes a non-voluntary - hence, morally arbitrary - limitation on the individual. This arbitrariness arises from the market heavily rewarding those talents and pursuits that happen to be economically profitable while disdaining the non-profitable ones that are nevertheless worthy according to non-market criteria (under the assumption that the value attributed to any individual's talents is not a reflection of his or her own actions or conceptions).

\section{Grounds for the duty to cooperate: a challenge}

At this point, a fundamental question arises as to how to establish the basis for an obligation to cooperate in the framework of a cooperative scheme of which we form part. Hart (1955, p. 185) provides a principle of mutual restriction as a source of such obligation:

when a number of persons conduct any joint enterprise according to rules and thus restrict their liberty, those who have submitted to these restrictions have a right to a similar submission from those who have benefited by their submission.

Hart's principle has been fiercely criticised by Robert Nozick, who argues that only explicit consent grounds duties of cooperation. The fact you left a book on my doorstep inviting me to form part of your reading club, says Nozick, does not put me in an obligation to reciprocate and give you another book (or payment) in turn, since I did not ask to be a member of your club. This holds even if I truly enjoy, and would therefore benefit from, reading. Thus, 'you may not decide to give me something, for example, a book, and then grab money from me to pay for it even if I have nothing better to spend the money on', claims Nozick (1975, p. 95). 'One cannot, whatever one's purposes, just act so as to give people benefits and then demand (or seize) payment. Nor can a group of persons do this' (ibid.). It is clear from this example that unasked-for benefits, no matter how desirable, cannot be grounds for reciprocation.

Nozick, however, disregards the fact his arguments apply only to certain types of benefits, namely, excludable benefits. Excludable benefits are benefits that the provider can choose to whom to provide them. You can choose whether or not to include me in your reading club. Therefore, the benefits you distribute can be taken away from me at your will. In this scenario, it makes sense to 
demand explicit adherence to the scheme as a condition for reciprocation. If I decline to be part of your club, you have the means to cease the provision of benefits to me. But the situation is different when the benefits in question are non-excludable. When a cooperative scheme distributes non-excludable goods that means it is impossible or prohibitively costly to exclude those who do not contribute to their expense from enjoying those goods. Pure public goods are of this sort. ${ }^{5}$ Definitions of public goods vary widely, but they usually involve, at least:

- jointness in supply: if a public good is available for one member of the group for which it is public, then it is available to every other member at no cost to that other member

- non-excludability: if anyone is enjoying the good, no one else can be prevented from doing so without excessive cost to the would-be excluders ${ }^{6}$

- jointness in consumption: one person's consumption of the good does not diminish the amount available for consumption by anyone else

- equality: if everyone receives the good, everyone receives the same amount. ${ }^{7}$

The public goods literature tells us that when regulating cooperative schemes that distribute pure public goods, individuals are under a reciprocal obligation to contribute irrespective of consent (Arneson 1982; Klosko 1987). This obligation is an obligation of fair play and it is fundamentally informed by Hart's principle of mutual restriction. In situations of non-excludability, since it is impossible to direct the benefits only to those who contribute, it would be unfair not to demand that all contribute since all benefit. The duty of fair play typically applies to public goods because they are non-excludable. It is precisely because they are non-excludable that gives rise, in the first place, to the automatic moral duty to contribute (Arneson 1982; Maphai 1987).

Situations where the benefits are non-excludable and membership is nonvoluntary have motivated a wealth of philosophical thinking on the nature of cooperative obligations. Political obligation is the paradigmatic example: we do

\footnotetext{
5 Sea travellers benefiting from a lighthouse (the quintessential example of a moral good) have a moral duty to contribute towards its construction and maintenance precisely because its light is non-excludable. A lighthouse projecting an excludable right (suppose it beams an infrared light that only seafarers with special night-vision equipment can see, the sale of which the lighthouse operator controls) produces no duty of fair play. Instead, an explicit contract would be applied here, and a toll levied. See Segall (2005, p. 339).

6 Non-excludability does not entail jointness of supply, necessarily. Consider a pile of newspapers made freely available to all bystanders in the street. In practice, it is possible to exclude some from getting a newspaper, in which case the benefit is jointly supplied but non-excludability does not follow. See Cullity (1995, pp. 3-4).

7 This condition should be qualified, however, since it may be too strong. A public good may be of no use to people lacking the capacities necessary to enjoy it. For example, a public park is of no use to someone who cannot get around; and public lighting is of no use to someone who cannot see. However, we can say that public goods are worth supporting on grounds of broader public utility.
} 
not choose to be born in a given country (and it is significantly costly to leave that country). How can we account for the obligation to cooperate - by abiding with the law - if we have not explicitly chosen to be members of the scheme? Social contract theories have resorted to the notion of tacit consent in order to ground political obligation but the public goods literature saves us from using such a dubious concept. The public goods literature tells us that (Arneson 1982, p. 623) where a scheme of cooperation:

is established that supplies a collective benefit that is worth the cost to each recipient, the burdens of cooperation are fairly divided, and were voluntary acceptance of the benefits is impossible, those who contribute their assigned fair share of the costs of the scheme have a right against the remaining beneficiaries that they should also pay their fair share.

This revised formulation of Hart's principle preserves the idea that accepting or even simply receiving the benefits of a cooperative scheme can sometimes obligate an individual to contribute to the support of the scheme, even though the individual has not consented to such scheme. The source of the obligation is the fact the benefits produced are non-excludable (all receive them) and desirable (all need them). ${ }^{8}$ It follows that cooperative schemes the fruits of which are excludable do not justify an automatic duty of reciprocity; they simply give rise to an acquired obligation.

In justifying a duty to work in return for welfare benefits, many thinkers argue that social wealth should be seen as a non-excludable (public) good. The idea that the creation of social surplus from which all individuals in society benefit justifies a duty to cooperate is espoused by Stuart White when he argues for the idea of 'normative non-excludability' (White 2003, p. 61). This idea draws from a technical concept common in the economic public goods literature, that is, the concept of excludability. At this point, it is worth quoting White (ibid.):

in egalitarian pictures of the good society, the tendency is to view the whole social product as having a quality of normative non-excludability that is analogous to the non-excludability characteristic of public goods. The social product is, if not a public good, what we might call a shared good: a good that everyone is presumptively entitled to share in to a more or less equal (or more or less equally needs-satisfying) extent. Every output is supposed to be in the collective pot (or to follow Winstanley, warehouse) for all to share equally in. When the social product is viewed in this light, however, worries analogous to those of public goods freeriders arise. The thought arises that, as with public goods, if the benefits of collective effort are going to be shared, so too should be this effort.

8 Assuming that desirability springs from need. 
In the same vein, Joseph Carens, another defender of the ethics of social duty, writes (Carens 1986, p. 37):

[t]he high level of production created if all or most citizens make good use of their talents and skills may be regarded as a collective good in an egalitarian society. People may desire the affluence that will be created if all contribute, but in the absence of shared and effective sense of social duty, each might be inclined to be a freerider and shirk.

There is something fishy about the line of reasoning espoused by White and Carens. If we reflect on the nature of the so-called 'social product' in market societies such as the ones in the Western developed world, we will realise that White's and Carens's descriptions are faulty. The non-excludability arguments that apply to public goods arise out of a fact of reality, namely, that it is impossible to exclude people from benefiting from that type of goods. Is this the case with social wealth more generally? It is not, unless we live in a kibbutz or a similar communal arrangement that is based on egalitarian distribution after production. ${ }^{9}$ In other words, in our society, people have to earn their living through work, and what they receive in return will be proportional to how much, and which type of, work they do. In societies of the sort we are used to living in there is no common pool or warehouse that guarantees to each of us a share of the social product. With the only exception of those public goods that flow to all irrespective of contribution (for example, national defence, clean streets, and public parks), the individual is not free-riding if he or she does not participate in the productive activities of society (being perfectly able to do so). By not participating, the individual will not be able to buy the food he or she needs to suppress hunger, nor to afford the housing he or she needs to protect himself or herself from the inclemency of climate.

In the framework of a kibbutz-like arrangement of the sort White is (allegedly) presupposing, there is, in actuality, a process of common accumulation and posterior distribution. But such communal process does not take place in market capitalistic systems. People are certainly going to demand that each member of the kibbutz cooperates, but if the individual immorally decides to disobey that duty (and nobody else realises this), the individual will receive the benefits produced by the effort of others at the end of the day, not only public goodswise, but also in terms of food and other basic supplies. This is not likely to occur in larger societies not ruled by the common pool logic. In those societies,

9 It has been suggested to me that my interpretation of White is wrong because he should be taken to say that if we had a society in which all wealth was treated as a common pool and divided equally, that would generate a duty to contribute. This observation is mistaken, however. If White's words are read carefully, it is clear he says that society as it is now should be seen in the light of the common pool interpretation. White argues that the tendency is to view the actual social product as a common pool resource. This is logical since White's aim is to justify a duty to cooperate in actual society, not in a hypothetical scenario. 
if you decide (for no impairing reason related to disability) to withdraw from economic cooperation there is little you can do to avoid deprivation eventually, even if nobody in the whole world becomes aware of your change of lifestyle. ${ }^{10}$ Furthermore, private property alones impedes the common pool logic from becoming a reality: Property rights serve as a means of excluding some from enjoyment of social wealth since these rights establish rules of appropriation and sanctions - that give rise to claims of ownership - and reparation - in the eyes of the law, and separate the 'haves' from the 'have-nots'. Indeed, there is no more clear example of an institutional mechanism that literally bars some from directly accessing wealth created in society. This means social wealth is not fully comparable to a public good in real life: It does not accrue equally to all after being generated (equality requirement specified above). The idle rich exemplify this. Their cooperation is close to null but their share of benefits is proportionally larger than their cooperative burden.

Social wealth is neither characterised by jointness in consumption, for a person's consumption of social wealth does leave less social wealth for others, on many occasions. If I preclude you from entering my property, for example, you will have less space in which to be and develop. Additionally, although money makes the finitude of land and the spoilage of natural resources less of a relevant constraint, as John Locke (1967) argued in his classical Second Treatise of Government, money does not confer on the dispossessed the type of control that ownership confers on the propertied. This is so because there is no title to money, so no rights associated to it as a possession.

The compulsoriness characteristic of traditional pure public goods is neither present in the case of social wealth. Benefits of social cooperation largely accrue to oneself by means of one's work. Receipt of the good produced by the scheme of cooperation is not automatic and is independent from other people's situation as to the good: the fact others receive the benefits does not mean I cannot avoid doing so at high cost. If I do not work, I will not receive the benefits. ${ }^{11}$ Therefore, we have established that, real public goods aside, the social product is excludable. The fair play duty (Hart's principle of mutual restriction) cannot be invoked to justify an obligation to work in societies of the sort with which we are most familiar. This does not mean that no reprimand can be justified for noncooperators, but the sanction cannot include denying individuals the means necessary for economic survival, namely, an income. It does not follow from all this that conditionality in the provision of welfare goods is ever unjustified, but it does follow that it cannot be justified on the basis of a civic duty to work.

\footnotetext{
10 Assuming the absence of independent wealth.

11 White's claims about normative non-excludability apply to society as we know it, not to society as it should be in an ideal world. I argue that his account of how distribution takes place is flawed. In this sense, the duty to work is not justified as long as society's product continues to be distributed as it currently is, that is, on the basis of one's employment situation, primordially.
} 
The foregoing conclusion is very important to understand why free-riding on those who work is not necessarily in tension with justice. In the context of our discussion on work, there are no ethical grounds to consider that reciprocation is required since the individual does not automatically benefit from the work of others regardless of the individual's efforts. If the individual does not work, he or she does not eat. Social wealth is largely excludable. Thus, the case at hand is one in which membership to a given scheme is non-voluntary but benefits are excludable. Social wealth, broadly understood as the collective production of the means to livelihood, is not like national defence (a pure public good) because it is not conferred on us regardless of whether we cooperate. That social wealth is excludable challenges the idea that an automatic obligation to cooperate in its making is due to society.

Justifying financial support when not cooperating, however, requires a more complex argument than the reasoning in the previous paragraphs offers. Such support constitutes a positive requirement on others, not a negative claim to freedom from cooperation. It is one thing to say that I am not required to cooperate because the benefits in question are excludable, but it is quite another thing to demand that cooperators support me. Why should individuals who contribute to the creation of social wealth actively pay for my non-cooperation? To answering this question I now turn.

\section{A positive duty of support}

My answer builds on basic principles of liberal egalitarianism. Specifically, it is based on a principle of rectification for morally arbitrary disadvantage. In discussions about social justice, compensation for this type of disadvantage motivates elegant and complex theories of distributive equality. In different ways, egalitarian theorists are concerned with limiting the effects of moral arbitrariness by minimising the advantage gaps that the latter causes. They may not all agree on what it is that should be equalised to attain that goal, but they all concur in the thought that morally arbitrary disadvantage is one source of unjustified inequalities.

Morally arbitrary disadvantage is triggered by factors that, one could say, it is reasonably to suppose the individual has no control of, such as gender, place of birth, ethnicity, and family's social background, to name a few. This lack of control has been referred to as 'brute luck' (Dworkin 1981). The occurrence of an event, or attribute, is due to brute luck to the extent that the agent could not have (reasonably) influenced the possibility or probability of its occurrence. This of course raises questions about what 'reasonably' exactly amounts to. However, the general intuition is that the presence of a capacity to exert control 
legitimises holding the individual to some degree responsible for a certain result. In this sense, distributions and states of affairs are just only when they result from decisions people make under 'controllable' conditions.

A preoccupation with morally arbitrary factors reflects how Rawls, most prominently, views the distribution of natural talents and luck more generally in his 'original position', an ideal hypothetical situation evoked to legitimise impartial and acceptable to all principles of justice (Rawls 1971). Parties to the original position know nothing about their particular social and personal circumstances, so acting rationally they will choose principles of justice that will not allow the most fortunate among them to take advantage of their special situation (for example, their superior wealth, intelligence, better health, and more convenient geographical location). This idea is a cornerstone of Rawls's egalitarianism, and, although it has given room to endless interpretation and debate, it is clear that it is rooted in a concern with alleviating disadvantages that are traced to factors the individual as a moral agent has done nothing to deserve or not deserve, because they lie beyond the scope of moral responsibility. This means that attaching blame or praise for their existence is senseless, philosophically. One can discuss the extent to which particular situations are uncontrollable, but the truth is that it is not hard to think of examples that confirm Rawls's concern: People usually may not be held responsible for their gender, socioeconomic familial background, place of birth, or innate talents, insofar as they have done nothing to enjoy or suffer the social consequences of these characteristics. Rawls objects to social arrangements and their underlying principles of justice that allow people to compete for available positions and advantages making no attempt to compensate for deprivations that some individuals suffer due to social contingency and natural chance, that is, due to factors attributable to moral luck, beyond the responsibility of the agent.

That society facilitates the exercise of certain activities and not others is a matter of moral arbitrariness from the individual's point of view. It is arbitrary that the system in which I live does not reward the type of talents I enjoy practising while it rewards the talents that other people enjoy practising. Nobody has done anything to deserve or not deserve this type of fortune - just as nobody has done anything to deserve being born a citizen of Norway instead of Somalia. And this arbitrariness is unfortunate because most people enjoy developing and exercising skills and abilities they possess or want to possess. It is not farfetched to think that most people, regardless of culture and political leaning, will desire to have those higher-order needs fulfilled to some important degree. Rawls's reference to the Aristotelian principle, a psychological law of motivation, reflects this assumption. The principle reads, 'other things equal, human beings enjoy the exercise of their realized capacities (their innate or trained abilities) and this enjoyment increases the more the capacity is realized, or the greater 
its complexity' (Rawls 1971, p. 426). The free-riding possibility that refusing cooperation in the creation of social wealth implies does not necessarily have to be seen in the light of an intention to minimise effort and retain gain, but as an opportunity to transit the road of self-realisation understood as a developmental human need. ${ }^{12}$

Many societies of today offer great opportunities for self-realisation in the form of meaningful work. Those opportunities are characteristic for being highly rewarding (materially, psychologically, or both) and for being socially necessary and appreciated by the public. It is this very fact that invites reflection on the situation of individuals who will not, through no fault of their own, have an opportunity to contribute to society while achieving self-realisation. The manner in which current societies are organised represents a morally arbitrary disadvantage for people whose self-definition hinges on the practice of talents and skills for which the market, or society more generally, finds little or no appreciation. To see this clearly, think of the following example.

John is a surfer who lives in Malibu and surfs all day long because he finds the exercise of his surfing talent extremely fulfilling. His surfing skills are so amazing that he regularly manages to attract a crowd of spectators who would be willing to pay to see John display his marvellous talent. Since the beach John surfs at is a private beach (which belongs to his dear friend Paul) John decides, with Paul's approval, that he will start charging spectators a small fee and devote the proceeds to charity after retaining some of the money to pay for food and board. John is generating economic gain that clearly contributes to society's general wealth. Now picture Matt, an experienced and passionate trumpet player who desires to live off his talent and help others, as John does. He mounts performance shows in his garden but nobody shows up to listen to him play. In Matt and John's society people are averse to trumpet playing, they find it boring.

These trivial examples illustrate one non-trivial normative conundrum: the specific type of social arrangement in which John and Matt live is favourable to John's self-realisation because it couples it with satisfaction of other people's (legitimate) preferences, which allows John to create wealth. But it is not equally favourable to Matt's self-realisation because Matt has an unappreciated skill. How arbitrary is to deny Matt a fair opportunity to exercise his talent and subsist because his abilities are not as acclaimed as John's? Differently put, how

12 For a pluralist, non-metaphysical, view of self-realisation, from which I draw, see Dewey (1893). The conception of self-realisation through the use of talents, understood as a higher-order developmental need is inspired by the widely accepted psychological theory of Abraham Maslow. See Maslow (1943). 
morally responsible for his contributive inclinations is John compared with Matt? It seems as if the social system made it much easier for John to comply with duty; and this rings unfair. ${ }^{13}$

Being able to exercise one's talents while contributing to society is relative to a cooperative framework (Buchanan 1990). And cooperative frameworks are chosen, reformed, and built by humans. Thus, it makes sense to say that it is a matter of collective choice what type of cooperative arrangement is established in a society. Therefore, the nature of such cooperative arrangements - whether they are biased in favour or against certain practices and talents is a matter of justice, not nature. Different cooperative arrangements demand different skills, and make certain skills appreciated and needed in comparison with other abilities and predispositions that may not be considered equally useful for cooperation. For example, a penchant for artistic pursuits may imperil self-fulfilling contribution under a market system highly focused on industrialised and technological progress in which more humanistic skills are usually unappreciated. However, artistic abilities may flourish in tandem with cooperation in societies where education and economic production are more diversified in their goals. If human development is an important social goal, however diversely understood such a concept is, we must acknowledge that the ways in which society facilitates or truncates the exercise of our skills and talents are philosophically (and by implication politically) important.

The arbitrariness of a cooperative scheme that is biased against certain talentholders is accentuated if we add to the picture the fact that membership to the scheme is not voluntary. We are born under a given socioeconomic system, and it is extremely difficult to exit it without risking survival: we have to feed ourselves and fulfil our basic needs. We cannot afford to exit under normal circumstances in the absence of independent wealth to sustain our withdrawal. Because of the high costs of leaving the scheme, it makes sense to say that membership is involuntary in a substantial sense. My claim is that it is the co-existence of this non-voluntariness and the bias of the scheme in favour of certain talents and dispositions that call for a positive duty of support. To elaborate on this claim, I have to go back to Hart.

In his reflections on contributive obligations, Hart is oblivious to the nature of the scheme of cooperation. The formulation of his principle makes no reference

\footnotetext{
13 It may be objected that Matt's disadvantage is only due to the random fact that preferences are aligned such way that his talent is not appreciated, but that is a question of luck, not justice. To this I reply that an economic system which permits the distribution of self-realisation to hinge on randomness is unfair. Thus, I am not criticising preferences as unfair, but that which the system makes of those preferences. A parallel reasoning can be found in Rawls's reference to a social system that compensates for natural and social contingencies. He says that people's natural endowments are 'neither just nor unjust; nor is it unjust that men are born into society at any particular position. These are simply natural facts. What is just or unjust is the way that institutions deal with these facts' (Rawls 1971, p. 102).
} 
to the aim of the scheme, only the distribution of burdens and benefits within the scheme are the object of fairness. To reiterate, Hart's principle reads (Hart 1955, p. 185):

When a number of persons conduct any joint enterprise according to rules and thus restrict their liberty, those who have submitted to these restrictions have a right to a similar submission from those who have benefited by their submission.

Hart emphasises the importance of a fair distribution of cooperative burdens and gains, but refrains from making mention of any justice requirement beyond the allocation of effort and benefits among the members of any scheme. A fair distribution of cooperative burdens, one would think, consists of a proportionate relationship between effort and gain for each individual cooperator. This means free-riding should be condemned because it violates this rule: it brings a larger share of benefits than the effort realised justifies. It does not constitute 'a similar submission' to the 'restrictions' imposed by the scheme, in Hart's terminology.

Rawls, in his reflections on fair cooperation, includes new features not developed by Hart in his principle of mutual restriction. According to Rawls, the benefitconferring scheme must be a just one, as interpreted under the logic of his two principles of justice. Rawls calls this qualified Hartian principle the principle of fairness'. In advocating this principle of fairness, Rawls, in A Theory of Justice, refers to the following argument (1971, pp. 111-2):

a person is required to do his part as defined by the rules of an institution when two conditions are met: fist, the institution is just (or fair), that is, it satisfies the two principles of justice; and second, one has voluntarily accepted the benefits of the arrangement or taken advantage of the opportunities it offers to further one's interests.

Building directly on the Hartian principle of restriction, Rawls's principle of fairness reads (1971, p. 108):

when a number of persons engage in a just, mutually advantageous, cooperative venture according to rules and thus restrain their liberty in ways necessary to yield advantages for all, those who have submitted to these restrictions have a right to similar acquiescence on the part of those who have benefited from their submission.

Rawls seems to suggest that injustice in the rules of cooperation weakens the moral obligation to contribute to the cooperative scheme. Note that this type of injustice is content-based, not procedural. This is to say that a scheme is unjust if its goals are detrimental, unfairly, to the interests of a certain group of people. The injustice would be procedural, on this stipulation of the terms, if the 
scheme's allocative rules were unfair to some individuals because they imposed a greater burden on them but did not grant a benefit commensurate with those individuals' greater efforts, even if the ultimate goals of the arrangement were overall just. (Think, for example, that the scheme of cooperation is a non-governmental organisation whose mission is the alleviation of poverty in disadvantaged urban areas, but the employees with more responsibilities are paid less than those with smaller responsibilities.) The justice that Rawls's principle of fairness refers to is concerned with the goals of the rules themselves even if the allocation of benefits among the cooperators is fair. For example, one would be hard-pressed to think that a band of bank robbers constitutes a just cooperative enterprise only because each member of the group is in charge of an equally hard and effort-demanding task. The group's objectives are at odds with norms of justice because robbery generally is.

Taking society as a cooperative scheme, it is possible to identify injustice if rules of cooperation prejudice certain individuals for no ethically valid reasons. Biased rules of cooperation, unlike an unfair allocation of the burdens of cooperation, direct the efforts of contributors towards ends that some wouldbe cooperators have legitimate grounds to find objectionable. Their objections may be of two kinds, in broad terms: comprehensive or contextual, I stipulate. The former applies to the nature of a given encompassing goal or character associated with a scheme of cooperation. The person objects to this goal, or rationale, because he or she finds it morally repulsive with independence of its effects on his or her individual life-situation. Someone may find racism morally repulsive even if, in strictly self-interested terms, that institution is beneficial for him or her (because it excludes a sizable portion of the population from the pool of competitors for certain coveted posts and social stations, for example).

A contextual-type of objection, in turn, does not necessarily imply moral condemnation, but the realisation that a given goal is relevantly detrimental to one's interests in such way that accepting it impedes the attainment of goods one has a moral claim to enjoy, under normal circumstances. For this reason, the contextual objector does not object to the existence of the scheme as such (on the basis of its overall immoral or unjust goals) but to the lack of alternatives to the scheme, that is, to the absence of freedom to refrain from (fully) participating in it.

If it is possible that a cooperative scheme is associated with unjust overall goals and rationales (at least from a contextual perspective), it is also reasonable to raise a moral objection against the obligatoriness of contribution. Whichever conceptualisation of social justice we hold, we do not need to completely adhere to Rawls's theory of justice in order to rely on his intuition that the goals of the cooperative scheme are important in assessing the morality of non-cooperation. It is important that we show concern for the substantive justness of the rules 
of cooperation (that is, the nature of its goals). This justness is surely a question of degree. In relation to this, the following question arises: what types of injustices, and what degrees thereof, loosen the force of the obligatoriness of cooperation in the creation of societal wealth? Rawls does not directly deal with this question because he stays at the level of generality. Anything that falls short of his two principles of justice is supposed to be unjust and grounds for reluctance to cooperate, in principle.

This chapter develops the argument that it is conceivable that a society that does not guarantee equal opportunities for the exercise of meaningful talents be regarded as unacceptably unjust, all things considered. I rest my claim on the idea that any institutional arrangement that truncates equal distribution of opportunities to fulfil central human interests looks suspicious from a substantive justice viewpoint. We have already established that the exercise of talents may be regarded as one such type of interest, founded on a higherorder human need, namely, the need to use our human potentialities, as Rawls's Aristotelian principle suggests. ${ }^{14}$

Rawls's principle of fairness seemingly leaves the individual free to refuse cooperation when the scheme to which the individual belongs is unjust, or when it presents elements of injustice that cannot be accepted. However, nowhere in his principle of fairness does Rawls explicitly offer grounding for a positive duty on the part of contributors to finance non-contributors. In what follows, however, I argue that Rawls's principle of fairness can be invoked to justify financial support for those who desire to enjoy freedom from social cooperation through the receipt of unconditional welfare goods (of which the basic income scheme is an example).

Under a system that rewards certain skills but not others, some people will find it easy to make a livelihood while others will have to forsake self-realisation to secure the means necessary for survival. This disadvantage is due to no fault of their own, it is 'morally arbitrary'. If this moral arbitrariness could be amended by relaxing the obligation to cooperate, we would end this discussion here. However, relaxing cooperation is not sufficient since the cooperative scheme guarantees survival only through work. This means that subjection to the rules of cooperation is non-voluntary. It is extremely costly to exit the cooperative scheme owing to a lack of other acceptable alternatives. ${ }^{15}$ Thus, we are faced with

14 The relationship between 'interests' and 'needs' is not self-evident, and calls for specification. It is reasonable to think that needs and interests may not always imply each other, for someone may have interests that are not supported by needs (in the sense of fundamental and universally recognizable necessities). However, one would be hard-pressed to deny the idea that needs give rise to a concomitant interest in their fulfillment under normal circumstances (assuming minimal rationality and absence of conflicting considerations).

15 For the notion of 'acceptable alternative', see Cohen (1988). 
the problem of how to compensate for the moral arbitrariness of a cooperative scheme that is biased in favour of certain talent-holders when mere freedom to abstain from cooperating does not suffice as a means to redress.

In view of this difficulty, the only way to compensate for the bias is to award the material means that will preclude slavery to the system. Because of the particular nature of the inequality, the negative liberty to abstain from cooperating must be complemented by a positive duty of support. This positive duty is grounded on the non-voluntary nature of the (unjust) scheme. Insofar as survival can be secured only by cooperating, nothing short of a positive compensation for having talents the scheme does not reward can serve justice. Limiting any principle of rectification to freedom from cooperation would address only half of the moral arbitrariness in question: it would relieve individuals from the burden of contribution, but it would also leave them to die while free. The point of conceiving of self-realisation as a central human interest is to highlight the desirability of full human development. It is dubious that this goal can be attained when others refrain from imposing on us certain activities if such refraining does not go hand in hand with effective opportunities to make use of our freedom. The excludability of social wealth grounds our freedom not to cooperate, but since the scheme is non-voluntary, in the sense that it is unacceptably costly to exit it, a positive duty of support to make that freedom real as opposed to merely formal is called for.

Thus, to recapitulate, let me summarise the argument based on Rawls's principle of fairness: a concrete policy that relaxes the centrality of employment as a social duty of reciprocity is justified on the basis of two elements. The first element is the injustice given by unequal access to self-realisation opportunities in society (in tension with Rawls's requirement of justice applied to the cooperative scheme). The second element is the fact that membership in the scheme of cooperation is non-voluntary. Therefore, permission to refrain from cooperation does not suffice to mend the above-mentioned injustice (this reflects my principle of active support).

At this juncture, the question whether the exercise of 'expensive talents' should be given room arises. If equality of access to self-realisation through the use of talents is a legitimate social goal (as Rawls's allusion to the Aristotelian principle seems to suggest), one may wonder how society is to accommodate all the different ways in which people will want to reach self-realisation. Some of those ways are going to be expensive in comparison with others. Should society make them all possible? If individuals are going to be treated with equal respect, it follows that their specific claims to self-realisation have to be taken into consideration on an equal footing. But how can this be possible if, in the 
context of budgetary limitations, some people will need many more resources than others to achieve self-realisation? (Some will want to be writers, while others will want to be epic film directors, for instance.)

The funding that society offers to its members should allow them, if desired, to pursue activities and projects that require the active exercise of an ability or skill that is normally enjoyed and relatively challenging to use (in keeping with the spirit of Rawls's Aristotelian principle). But this does not mean that society should necessarily fund any particular pursuits that individuals desire to engage in. It is crucial to justice that the agent, being free to choose which talent to develop, be in a position to enjoy the background capabilities that are necessary for self-realisation. The latter include, among others, a certain degree of autonomy, space for creativity, non-repetitiveness, and a sense of responsibility for the final product of using one's talents. The individual should be free from market constraints so that he or she has the opportunity to experience the meaningful exercise of his or her powers if her self-realisation entails, in some way, the use of non-marketable skills. To honour equality of respect on the part of society towards its members, the individual's capacity to exercise his or her talents should be decoupled from other people's conceptions of that which is of value or desirable, at least partially. However, this justice requirement does not permit funding for any one particular activity or plan that is a vehicle to self-realisation. It is a human interest to be able to exercise one's talents minimally autonomously and with independence of their popularity, but it is not a human interest to exercise one's talents in one and only one way. Justice warrants equal access to the conditions of self-realisation, but it also warrants that such access be equally distributed among all members of society. These two potentially conflicting requisites justify limitations on the claims to self-realisation. Not all particular paths to self-realisation can, or should, be guaranteed to the individual. However, society should see to it that minimal conditions favourable to the attainment of self-realisation for all exist.

Since my views reject the idea that individuals with more expensive selfrealisation needs should get more resources, they are not archetypically 'welfarist'. ${ }^{16}$ This rejection is rooted in a philosophical premise, not in circumstantial considerations of costs. The premise is that only fundamental interests should be the primary focus of distributive justice. ${ }^{17}$ Those interests have an objective aspect that in the case of self-realisation is given by the universally recognised human need to exercise one's talents autonomously and in a challenging way. It is a human interest to be able to exercise one's talents

16 Welfarist conceptions of equality take preference formation or subjective desire as the yardsticks of dsitribution. For an overview of these views, see Dworkin (1981)

17 For a non-subjective approach to distributive justice based on the concept of 'fundamental human interests', see Scanlon (1975). 
minimally autonomously but it cannot be thought that every particular pursuit constitutes a fundamental human interest that all individuals could reasonably be said to share qua human beings.

Admittedly, the moral arbitrariness argument evoked to justify society's positive duty to make freedom from marketable work possible does not apply to individuals who have the option to engage in intrinsically satisfying work (that is, work that is conducive to self-realisation) but nevertheless prefer not to work because they are lazy. For the lazy, it is not at all clear that society has a positive duty of financial support to make their negative freedom from the obligation to cooperate sustainable, simply because a bias against laziness on the part of collective social arrangements does not count as creating morally arbitrary disadvantage that is relevant from the standpoint of justice. In keeping with the argument that self-realisation constitutes a generally recognised developmental need, I must say that it is not clear that laziness can contribute to fulfilling this need, since it does not imply the use of talents but rather the exact opposite. This conclusion is in stark contradiction with traditional leftlibertarian defences of unconditional welfare provisions - such as Van Parijs's - that are ethically neutral among work and non-work preferences. However, in the absence of a consistent-with-autonomy way to identify the non-deserving beneficiaries of unconditional welfare provisions, it makes sense to extend the policy to everybody, under the (quite realistic assumption, I believe) that a sizable part of the population will still desire to form part of the workforce.

\section{Conclusion}

My reply to the free-rider objection against unconditional welfare policies (such as the basic income scheme) revolved around the idea that if we take society as a cooperative scheme, its excludable benefits justify freedom to exit cooperation. Additionally, the scheme's non-voluntary nature gives rise to a positive duty, on the part of society, to fund such freedom. Rawls's principle of fairness, inspired by Hart's principle of restriction, is the philosophical building block for this view. To further ground a right to freedom from cooperation, I developed the argument that equality of opportunity for self-realisation through the use of talents is necessary to offset slavery to the 'marketability logic', which renders fulfillment of a higher-order developmental need impossible for many. That selfrealisation is partly associated with subjective preference - since there are many different ways in which it can be attained - does not mean that distributive justice should be concerned with all particular interests and desires, especially if they are unacceptably expensive. 
Finally, my arguments for self-realisation are not meant to obviate considerations of feasibility and conflicting social needs. Fulfillment of basic human needs such as nourishment, medical care, and shelter, to name a few, should always count as prior to any higher-order developmental needs such as self-realisation, if only for reasons of fundamental justice as well as humanity. Nevertheless, acknowledging some type of lexicographic ordering of human needs does not detract from the importance of self-realisation in a context in which (some) attention to it can legitimately be paid.

\section{References}

Arneson, R. 1982. 'The principle of fairness and free-rider problems.' Ethics 92(4): 616-33.

Buchanan, A. 1990. 'Justice as reciprocity versus subject-centered justice.' Philosophy and Public Affairs 19(3): 227-52.

Carens, J. 1986. 'Rights and duties in an egalitarian society.' Political Theory 14(1): $311-49$.

Cohen, G. 1988. History, Labour and Freedom. Oxford: Oxford Clarendon Press.

Cullity, G. 1995. 'Moral free-riding.' Philosophy and Public Affairs 24(1): 3-34.

Dewey, J. 1893. 'Self-realization as the moral ideal.' Philosophical Review 2(6): 652-64.

Dworkin, R. 1981. 'What is equality? Part II: Equality of resources.' Philosophy and Public Affairs 10(4): 283-345.

Elster, J. 1986. 'Comment on Van der Veen and Van Parijs.' Theory and Society 15(5): 709-21.

Hart, H. L. A. 1955. 'Are there any natural rights?' Philosophical Review 64(2): 175-91.

Klosko, G. 1987. 'Presumptive benefit, fairness and political obligation.' Philosophy and Public Affairs 16(3): 241-59.

Locke, J. 1967. Second Treatise of Government. Cambridge: Cambridge University Press.

Maphai, V. 1987. 'The principle of fairness.' South African Journal of Philosophy 6(3): $73-80$. 
Maslow, A. 1943. 'A theory of human motivation.' Psychological Review 50(4): 370-96.

Nozick, R. 1975. Anarchy, State and Utopia. Cambridge: Harvard University Press.

Rawls, J. 1971. A Theory of Justice. Cambridge: Harvard University Press.

Scanlon, T. 1975. 'Preference and urgency.' Journal of Philosophy 72(19): 655-69.

Segall, S. 2005. 'Unconditional welfare benefits and the principle of reciprocity.' Politics, Philosophy and Economics 4(3): 331-54.

Van der Veen, R. 1991. Between Exploitation and Communism: Explorations in the Marxian theory of justice and freedom. Amsterdam: Groningen.

Van der Veen, R., and P. Van Parijs. 1986. 'Universal grants versus socialism: A reply to six critics.' Theory and Society 15(5): 723-57.

Van Parijs, P. 1995. Real Freedom for All: What (if anything) can justify capitalism? Oxford: Oxford University Press.

White, S. 2004. The Civic Minimum: Rights and obligations of economic citizenship. Oxford: Oxford University Press. 